\title{
FLUOTHANE AND HYPOTENSION IN CATS ${ }^{1}$
}

\author{
Antta C. Beaton, M.D.
}

Among its several properties Fluothane possesses the ab lity to lower the blood pressure. This property has been reported in all the publis red work on Fluothane, clinical and experimental, although there has not been perfect agreement as to its severity and its relation to the dose of Fluothane. We have tried to investigate this hypotensive action of Fluothane in a manner that would throw some light upon how it is produced.

At the time these experiments were planned, only two reports of experiments with Fluothane were available. Raventos (1) said that Fluothane seemed to act as a selective ganglion blocker and that cardiac output was unchanged at maintenance levels. The Committee on Non-explosive Anaesthetic Agents (2) in their report to the Medical Research Council said their investigations indicated that the hypotension was probably the result of a threefold action-central nervous system depression (vasomotor centre), myocardial depression, and a small amount of peripheral ganglion block.

Recently, more reports of experiments with Fluothane have appeared. Severinghaus and Cullen (3) felt that the hypotension is largely the result of myocardial depression and that, if anything, the reflexes exerted a compensatory effect. Krantz, Park, Truitt, and $\operatorname{ling}(4)$ found diminished amplitude and slowing of the frog's heart on perfusion with Fluothane. Long and Pettinger (5) suggest that myocardial depression contributes very significantly towards the production of hypotension.

The aim of our work was twofold: (i) to reaffirm the hypotensive action of Fluothane and the fact that its effect is proportional to dose; (ii) to determine the site of action of Fluothane in producing this hypotensive effect, first by the use of autonomic blocking drugs and then, if necessary, by a study of cardiac output.

These objectives resulted in the end in two types of experiments being performed. In the first group the effect of Fluothane was measured on animals which had received no medication other than chloralose. This experiment was followed by observation of effects in animals that had received a variety of blocking drugs: hexamethonium bromide, d-tubocurarine, dibenzyline, and combinations of these. The basic method was the same throughout and the effects of Fluothane were observed on blood pressure, heart rate, respiratory rate and depth, and the hypertensive response to common carotid occlusion. In addition, the appearance of cardiac arrhythmias was noted though no attempt was made to determine their nature. The animals used throughout were cats. This presents a possible difficulty in comparing our results with those observed in humans as the cat is predominantly a sympathetic animal and there have been some features of the effects of Fluothane suggestive of a parasympathetic effect.

Marked depression of respiration was noted as a result of administering C6 and dibenzyline to the same animal and from the higher doses of Fluothane.

${ }^{1}$ From the Department of Anaesthesia, University of Toronto. 
In order to determine whether this decrease in ventilation, with possible hypoxia and hypercarbia, had any effect on the response to Fluothane, carbon dioxide was given to some blocked and ventilated animals.

The second group of experiments dealing with cardiac output gave, in addition, measurements of respiratory rate and depth, oxygen consumption, mean arterial pressure, heart rate, and from these, calculations of minute volume, total peripheral resistance (T.P.R.), and stroke volume.

\section{Group One: Use OF BlockINg Drugs}

\section{Method}

Adult female cats of an average weight of $2.84 \mathrm{~kg}$. were first given chloralose, $80 \mathrm{mg} . / \mathrm{kg}$. To most it was given intraperitoneally, but a few were given ether first to stun them. Each cat was connected to an anaesthetic machine delivering a 50-50 mixture of nitrous oxide and oxygen into a tracheal cannula. Rebreathing was considered to be negligible as an expiratory outlet of very low resistance was placed in close proximity to the tracheal cannula. The Fluothane was administered from a Fluotec vaporizer with the gas flow at a rate of $6 \mathrm{~L} . / \mathrm{min}$. Respiratory tracings were obtained by inserting a tambour with writing arm into the respiratory circuit. Arterial pressures were recorded from a cannula in the femoral artery attached to a mercury manometer and recording on a smoked drum. The right common carotid artery was freed for testing the response to occlusion. Once the experiment was set up and control tracings taken, Fluothane 0.5 per cent was administered for $10 \mathrm{~min}$. followed by a $10 \mathrm{~min}$. blow-off period. This procedure was repeated for 1.0, 1.5, and 2.0 per cent doses of Fluothane. In those animals being tested after the administration of blocking drugs, only one $10 \mathrm{~min}$. period of Fluothane was employed prior to the drugs to make sure of the reactivity of the cat to Fluothane. After a 10-min. washout, the blocking drugs were given intravenously and, when evidence of drug action appeared, Fluothane was administered in the same manner used with the unblocked animals. Where dibenzyline was used, it was given in a dose of $3 \mathrm{mg} . / \mathrm{kg}$., slowly intravenously, and block was considered satisfactory when reversal of response to $3 \mu \mathrm{g} . / \mathrm{kg}$. of epinephrine was obtained (6). Hexamethonium bromide was given in a dose of $6 \mathrm{mg}$. $/ \mathrm{kg}$. with the repeat of a half-dose every $20 \mathrm{~min}$. $(7,8)$. Inhibition of the hypertensive response to common carotid occlusion was looked for, but less than total inhibition was accepted, as in some cats we were unable totally to inhibit the reflex no matter what the dose. Curare was given in a dose of $1 \mathrm{mg} . / \mathrm{kg}$. (9) with a half-dose repeated every $30 \mathrm{~min}$., and seemed to be just as effective a ganglion blocker as $\mathrm{C6}$. The paralysed cats were ventilated by a positive-negative phase pump at a rate of 14 per min. and a volume of $30 \mathrm{cc}$. The two cats which received $\mathrm{CO}_{2}$ were first given curare and dibenzyline and their response to 1.5 per cent Fluothane recorded. After $10 \mathrm{~min}$. on the nitrous oxide-oxygen mixture, 4 per cent $\mathrm{CO}_{2}$ was added for $10 \mathrm{~min}$. and then 1.5 per cent Fluothane added in, and the response of blood pressure measured after a further $10 \mathrm{~min}$. This was followed by a $10 \mathrm{~min}$. washout period and then a. repeat dose using 7 per cent $\mathrm{CO}_{2}$. 


\section{Results}

From Figure 1 it can be seen that Fluothane lowers the blood pressure in doses of 0.5 per cent and higher and that the response is proportional to the dose. There was no significant change in the heart rate or in the respiratory rate. There was a definite and progressive depression of the respiratory depth with increasing doses of Fluothane (see Table II), and of the four cats tested with 2.5 per cent Fluothane, two developed respiratory arrest. There was also progressive depression of the hypertensive response to common carotid occlusion with increasing doses. Cardiac arrhythmias were seen in five of the sixteen cats which received increasing doses of Fluothane, one at 1.0 per cent, two at 1.5 per cent, and two at 2.0 per cent. All reverted to normal rhythm when the Fluothane was removed. Analysis of the animals which received only one dose of Fluothane as a test prior to the blocking drugs showed that the blood pressure returned to control levels after one 10-min. exposure. With exposure of longer duration, land certainly when higher concentrations were used, $10 \mathrm{~min}$. was not always (as suggested by Raventos) an adequate blow-off period when judged by a return of blood pressure.

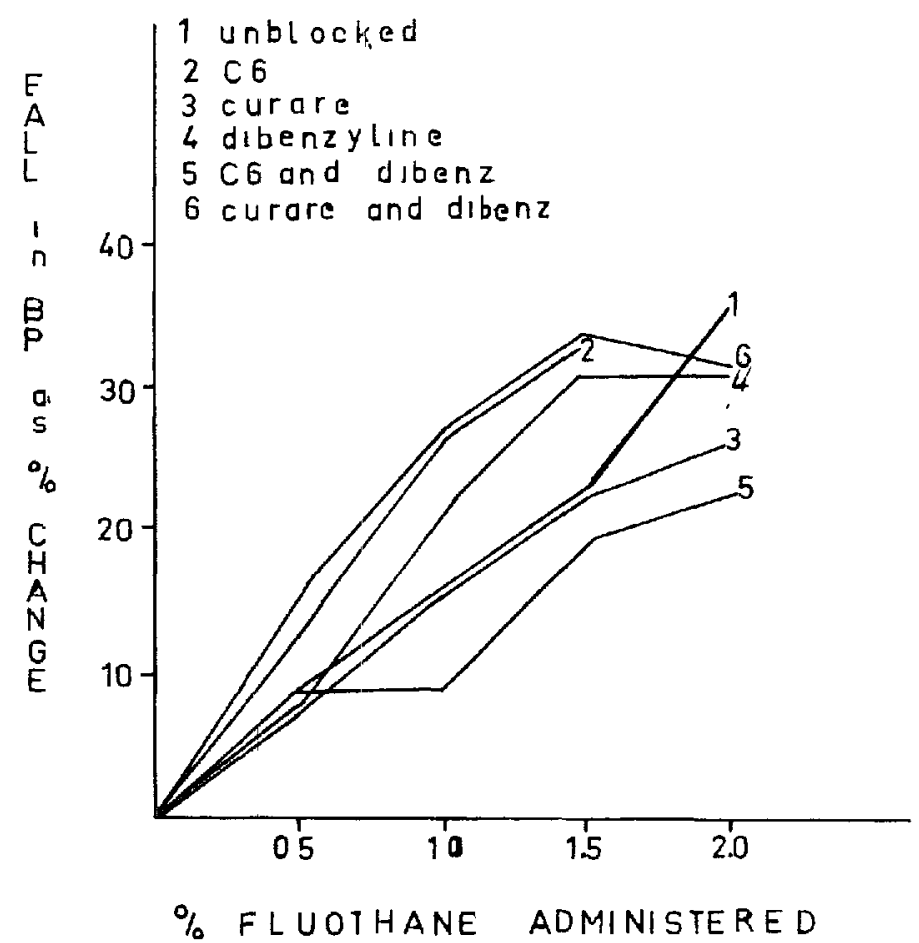

Figure 1 Blood pressure response in group one.

The effect of Fluothane on the blood pressure in the blocked animals did not differ significantly from the hypotensive effect in the unblocked cats. The only significant difference on analysis was between the response in the C6 group and the group that received both $\mathrm{C} 6$ and dibenzyline (Table I). In the blocked animals the depression of respiration by the Fluothane was still noticeable. Besides slowing the heart rate the blocking drugs tended to have other side 


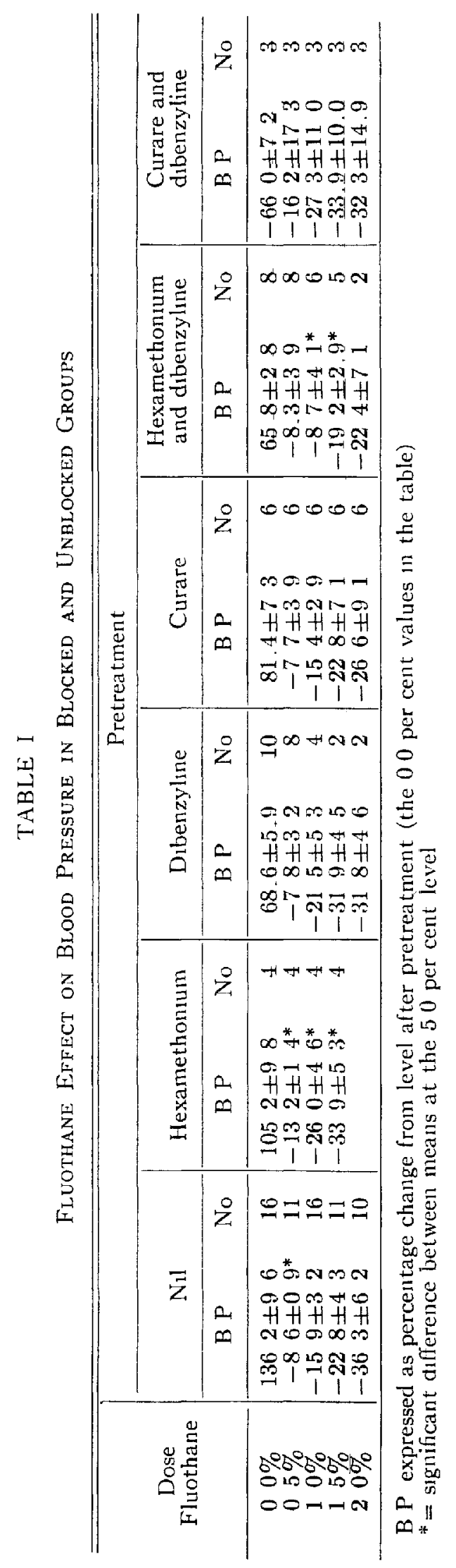


effects, the most notable being the depressant effect of C6 and dibenzyline combined on the respiratory rate and depth (Table II).

The administration of $\mathrm{CO}_{2}$ to the blocked and ventilated cats enhanced the effect of 1.5 per cent Fluothane to a degree that was the same for 4 per cent and 7 per cent; a fall of 16.9 per cent as compared to falls of 38.2 and 39.5 per cent respectively (see Fig. 2). Of interest is the antagonism to the hypotension produced by the blocking drugs shown by 4 per cent $\mathrm{CO}_{2}$. Slowing of the pulse occurred with the addition of $\mathrm{CO}_{2}$ and this effect was increased by the Fluothane.

TABLE II

Ventilatory hFFects in Blocked and Unblocked Groups

\begin{tabular}{|c|c|c|c|c|c|}
\hline \multirow{2}{*}{$\begin{array}{l}\text { Dose } \\
\text { Fluothane }\end{array}$} & & \multicolumn{4}{|c|}{ Pretreatment } \\
\hline & & $N_{1} \mid$ & Hexamethonıum & Dibenzyline & $\begin{array}{l}\text { Hexamethonium } \\
\text { and dibenzyline }\end{array}$ \\
\hline $00 \%$ & $\begin{array}{l}\text { Rate } \\
\text { Depth* }\end{array}$ & $\begin{aligned} 136 \pm 05 \\
1000\end{aligned}$ & $\begin{array}{rrrr}-0 & 8 \pm 0 & 1 \\
115 & 6 \pm 9 & 2\end{array}$ & $\begin{array}{rl}-2 & 8 \pm 09 \\
83 & 1 \pm 112\end{array}$ & 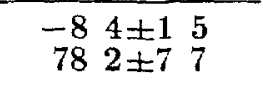 \\
\hline $0.5 \%$ & $\begin{array}{l}\text { Rate } \\
\text { Depth }\end{array}$ & $\begin{array}{rrr}-4 & 8 \pm 1 & 9 \\
942 \pm 3 & 6\end{array}$ & $\begin{array}{ll}0 & 0 \\
87 & 5 \pm 42\end{array}$ & $\begin{array}{rl}-2 & 7 \pm 14 \\
83 & 4 \pm 108\end{array}$ & $\begin{array}{rrr}-0 & 4 \pm 0 & 4 \\
78 & 4 \pm 3 & 7\end{array}$ \\
\hline $\begin{array}{l}10 \% \\
15 \%\end{array}$ & $\begin{array}{l}\text { Rate } \\
\text { Depth } \\
\text { Rate } \\
\text { Depth }\end{array}$ & $\begin{array}{rrr}-5 & 6 \pm 1 & 5 \\
74 & 6 \pm 8 & 7 \\
-6 & 6 \pm 2 & 3 \\
56 & 3 \pm 9 & 1\end{array}$ & $\begin{array}{rrr}+0 & 7 \pm 0 & 2 \\
85 & 4 \pm 7 & 3 \\
+2 & 0 \pm 0 & 4 \\
66 & 6 \pm 7 & 4\end{array}$ & 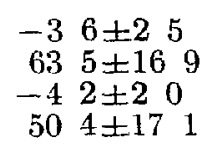 & $\begin{array}{rrr}-1 & 3 \pm 0 & 4 \\
63 & 5 \pm 5 & 4 \\
-1 & 6 \pm 0 & 4 \\
50 & 7 \pm 5 & 8\end{array}$ \\
\hline $20 \%$ & $\begin{array}{l}\text { Rate } \\
\text { Depth }\end{array}$ & $\begin{array}{rrr}-4 & 7 \pm 1 & 4 \\
46 & 5 \pm 9 & 1\end{array}$ & 5 & & $\begin{array}{ll}-2 & 4 \pm 06 \\
54 & 0 \pm 12\end{array}$ \\
\hline
\end{tabular}

*Respiratory depth is expressed as percentage When blocking drugs were given previously, Fluothane effect is recorded as percentage of respiratory depth resulting from those drugs

\section{Group Two: Measurement of Cardiac Output}

\section{Method}

These experiments were designed primarily to gain a measure of the effect of Fluothane on the cardiac output, and at the same time to obtain more precise measurements of the ventilatory effects. The Fick principle was employed. Adult cats of an average weight of $3.53 \mathrm{~kg}$. were used. Basal anaesthesia was established with intraperitoneal chloralose, $80 \mathrm{mg} . / \mathrm{kg}$. The trachea was cannulated and connected to a source of oxygen. When Fluothane was administered, it was from a Fluotec vaporizer with the flow of oxygen at a rate of $6 \mathrm{~L} . / \mathrm{min}$. A side-arm close to the tracheal cannula led to a Phipps and Bird small-animal spirometer. This was washed out and charged with the atmosphere the animal was currently receiving before each measurement of oxygen consumption. Each one of the connections, oxygen to cat, spirometer to cat, and oxygen to spirometer, could be easily opened and shut by means of a tap in each connection. The femoral artery was cannulated and connected via a three-way stopcock to an electromanometer recording on a Sanborn Pply-Viso. A small-bore polyethylene catheter was placed in the right side of the heart using pulsation and changes of pressure in a water manometer as the indicator of position. The arterial and venous 
samples were taken simultaneously over a 1 -min. period into oiled and heparinized syringes. The samples were $1.5 \mathrm{cc}$. each. All blood aspirated prior to the taking of the samples was returned to the animals and the total blood lost to the animal was considered to be not more than $30 \mathrm{cc}$. Oxygen consumption was measured over a 2-min. period and overlapped the taking of the blood samples. Samples were taken and tracings recorded for initial values, after $10 \mathrm{~min}$. of 0.5 per cent Fluothane, after a 10-min, blow-off period, after $10 \mathrm{~min}$. of 1.0 per cent Fluothane, after a 10-min. washout, and so on, for 1.5 per cent and 2.0 per cent doses of Fluothane with the blow-off period at the end $20 \mathrm{~min}$. instead of 10. Estimations of the differences in oxygen saturation of the blood samples were done using the Warburg apparatus and a method taken from Courtice and Douglas (10) and supplied by Dr. J. B. Armstrong of the Department of Pharmacology. Onehalf of the samples were assayed within $2 \mathrm{hr}$. of the experiment and the other half was stored on ice in the refrigerator and done within $24 \mathrm{hr}$.

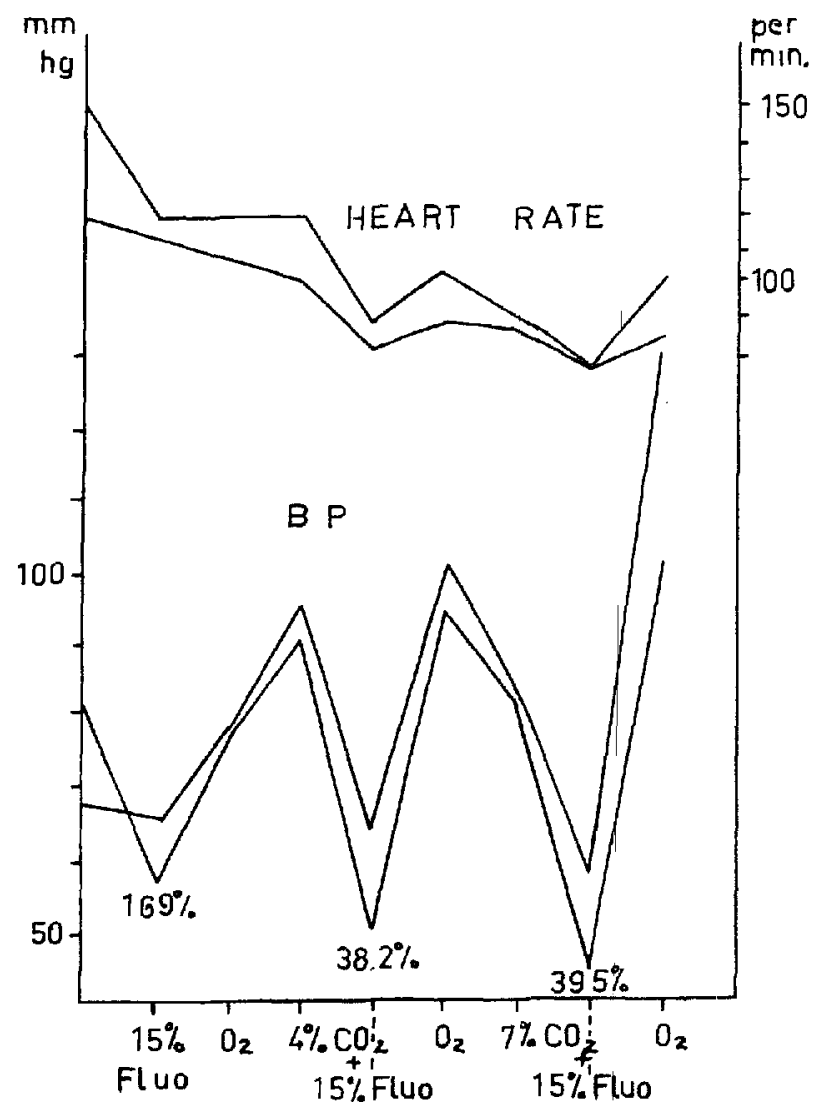

Figure 2. Effect of $\mathrm{CO}_{2}$ on response te Fluothane.

\section{Results}

The results are presented in Figure 3 and Table III. Oxygen consumption was essentially unaltered, as was the respiratory rate. Cardiac output appeared to be depressed by the Fluothane. In order to see if loss of blood necessitated by the method used was responsible for any of the changes in the functions of the cardiovascular system, in two cats, the blood loss was reduced by not taking 
1. 2.3.

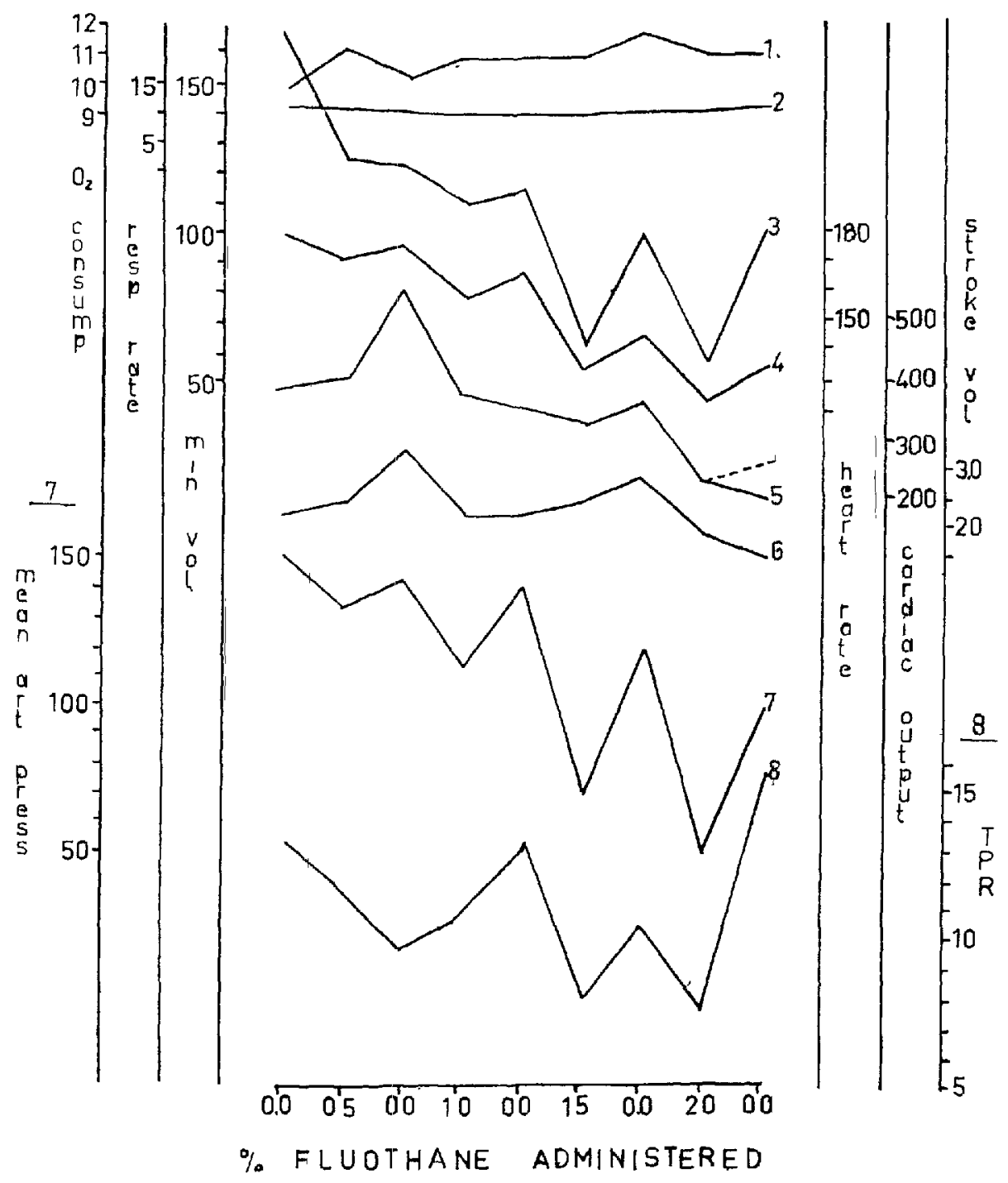

FIGURE 3. Effect on the respiratory and cardiovascular functions (the units are the same as those in Table III).

any samples at the end of the washout periods. The results were essentially the same; cardiac output showed the same response to increasing doses of Fluothane and, in addition, there was some recoverey at the end of the experiment. This is indicated by the dotted line in Figure 3. Minute volume showed a definite decrease as did mean arterial pressure, calculated total peripheral resistance, and, in this group, heart rate. Prólonging the washout period at the end of the experiment to $40 \mathrm{~min}$. did not produce any further recovery of blood pressure.

\section{Discussion}

From the results in group one, accepting the analysis for significance, it would appear that the hypotensive response to Fluothane is not materially changed by 


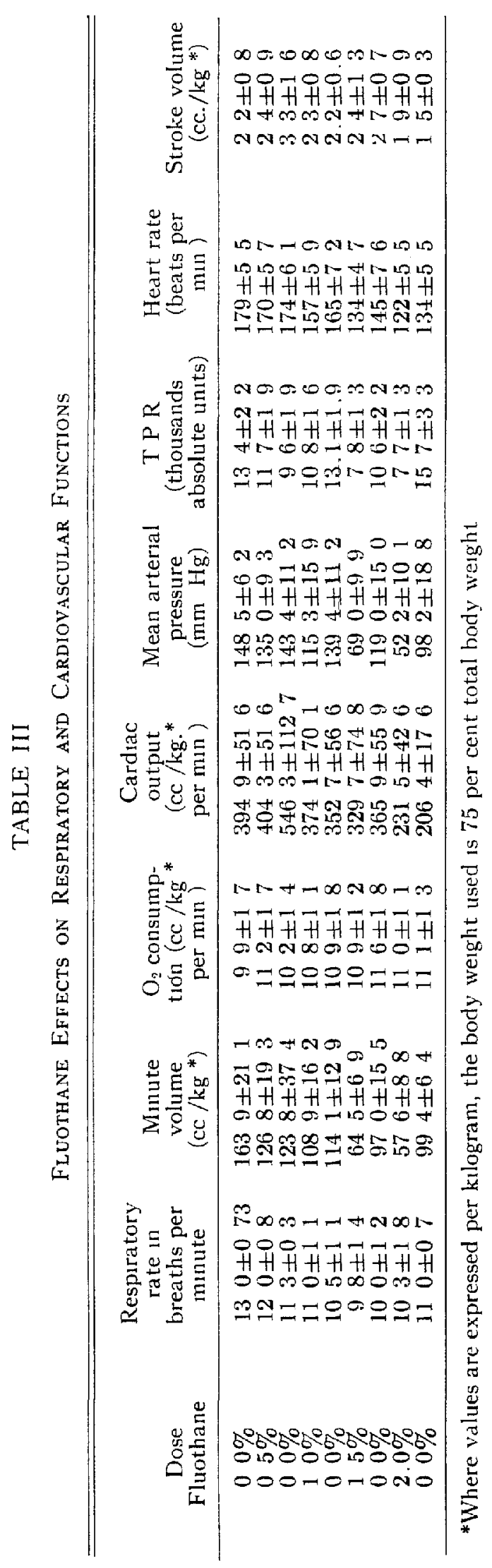


the use of autonomic blocking drugs and we can say that ganglion blockade and peripheral sympathetic blockade play no part in the production of the hypotension. The difference between the $\mathrm{C} 6$ and the $\mathrm{C} 6$ and dibenzyline combined groups can be explained by reference to Table II. While in all the animals, blocked and unblocked, ventilation was depressed by the higher doses of Fluothane, the combination of C6 and dibenzyline produced almost as much depression by reducing both rate and depth of respiration before any Fluothane was given, and we must assume that hypoxia, hypercardia, and inadequate exchange of vapour occurred and that this accounts for the difference. Reference to Figure 2 shows that $\mathrm{CO}_{2}$ enhances the effect of Fluothane on the blood pressure. In the underventilated C6 and dibenzyline group the opposite effect is seen. Hypoxia, then, is probably the explanation of this difference. This also was suggested by the response to manual assistance of respiration when it was carried out at the end of three of these C6 and dibenzyline experiments. This produced an elevation of the blood pressure generally with an increased response to Fluothane.

From these experiments so far it would appear that Fluothane exerts no effect on the reflex mechanisms, the vasomotor centre, the sympathetic ganglia, or the sympathetic peripheral nerve endings. Hence, direct action on the heart or the arterioles may be the means of producing the hypotension. While not statistically significant, the difference in slope between the plots of all the blocked group and that of the pressure changes with Fluothane in the unblocked cats is very suggestive that there may be a combined effect, and between a dose of 1.5 per cent and 2.0 peri cent in the blocked animals maximal dilatation of the arterioles occurred.

Inhalation of carbon dioxide in the blocked and ventilated cats definitely increased the hypotensive action of Fluothane, and in combination a definite slowing of the heart was seen. This could very well be an enhancement of the Fluothane action at both sites. The slowing of heart rate points to an action on the heart in the presence of $\mathrm{CO}_{2}$ at any rate. Perhaps Fluothane is an agent like cyclopropane with which $\mathrm{CO}_{2}$ accumulation predisposes towards the production of adverse cardiac effects (11).

If the results from the second group of experiments are considered, a definite slowing of the heart rate and no reduction of stroke volume point to a change in rate as the means of reducing the cardiac output at concentrations of 1.5 per cent or less, and suggest that direct depression of the myocardium does not occur until a toxic level of 2.0 per cent is reached. That Fluothene becomes toxic to the cat in doses of 1.5 to 2.0 per cent is fairly clear by reference to Figure 3 . Slowing of the heart rate and the electrocardiograph changes reported $(2,12,13)$ suggest some alteration in the functioning of the conductive tissue of the heart. Harris (14), in discussing the mode of action - of anaesthetics of high oil/water solubility co-efficients, of which Fluothane, is an example, sees the conducting tissue as the most readily affected portion of the heart. Curiouily, no significant change in heart rate was demonstrated in the first group of unb_ocked animals, but the,blood pressure still decreased.

In view of the fact that the use of blocking drugs demionstrated no act on by Fluothane reflexly, on the vasomotor centre, sympathetic ganglia, or nerva end- 
ings, a change in calculated total peripheral resistance must mean an effect on the arterioles. As this effect appears with a dose of 0.5 per cent Fluothane when it seems safe to assume that oxygenation and the elimination of $\mathrm{CO}_{2}$ are adequate it must be a direct effect of this agent on the arterioles. The respiratory depression, as it is not accompanied by any significant compensatory increase in rate, would seem to be the result of depression of the respiratory centre. As this appears with relatively low doses of Fluothane, can the other brain-stem centres remain unaffected for very long? Certainly, the accompanying hypoventilation, hypoxia, and hypercarbia, besides having adverse effects of their own, would seem, with $\mathrm{CO}_{2}$ at least, to intensify some of the bad effects of Fluothane.

\section{ConClusions}

The hypotension produced by Fluothane would seem to be the result of more than one action, with both the heart and the arterioles being a site. Depression of both the conducting tissue and the contractile tissue probably occurs and Fluothane has a direct dilating action on the arterioles. The degree of hypotension seen with increasing doses is a reflection not only of a true hypotensive action by Fluothane, but also of its interaction with the cardiovascular responses to the very definite depression of respiration produced in the cat with doses of Fluothane of 1.0 per cent or more.

\section{SUMMARY}

The hypotensive action of Fluothane in cats receiving autonomic blocking agents was compared with the response in unblocked cats. No effect on reflex mechanisms, the vasomotor centre, sympathetic ganglia, or nerve endings appears to play any part in the production of hypotension in the cat. Cardiac output in the intact animal receiving Fluothane was measured. From a consideration of both groups of experiments it would seem likely that Fluothane exerts its hypotensive effect by means of action on the heart and the arterioles. Coincident depression of respiration occurs.

\section{ACKNOWLEDGMENTS}

This work was financed by funds made available by the Department of Anaesthesia, University of Toronto, from a grant to the Department from the Insulin Fund. Thanks are due to the Department of Pharmacology whose facilities were freely extended to me that I might carry out the experiments, to British Oxygen Canada Limited who provided any anaesthetic equipment necessary, to Mr. Fraser Sweatman who loaned the Fluotec vaporizer and to Ayerst, McKenna and Harrison Limited who provided the Fluothane. I am indebted to Dr. J. B. Armstrong for help and information in the setting up of the experiments, to Dr. W. Kalow and Professor D. B. W. Reid for advice regarding the presentation of the results, and to Professor $H$. Cullumbine for his interest, encouragement, and helpful criticism throughout. 


\section{RÉsumé}

Nous avons comparé l'action hypotensive du Fluothane chez des chats qui avaient reçu des agents inhibiteurs du système nerveux autonome et chez des chats qui n'avaient rien reçu. Au cours de l'hypotension observée chez le chat, il ne semble pas exister d'action sur les mécanismes réflexes, ni sur le centre vasomoteur, ni sur les ganglions sympathiques, ni sux les terminaisons nerveuses. Nous avons mesuré le débit cardiaque sur l'animal intact soumis à une anesthésie au Fluothane. Si l'on fait un parallèle entre les deux groupes d'expériences, l'action hypotensive du Fluothane découlerait, selon toute vraisemblance, de son action sur le cœur et sur les artérioles. Nous avons observé une dépression respiratoire concomittante.

\section{REFERENCES}

1 Raventos, J Action of Fluothane A New Volatile Anaesthetic Brit. J Pharmacol 11: 394 (1956)

2 Committee on Non-Explosive Anaesthetic Agents. Fluothane A Report to the Medical Research Council, Brit Med. J 2. 479 (Aug. 31, 1957).

3. Severinghaus, J. W, \& Cullen, S. C. Depression of Myocardium and of Total Body Oxygen Consumption by Fluothane in Man. Anesthesiology 19165 (1958).

4. Krantz, J. C., Park, C. S., Truttr, E B.; \& Livg, A. S C. A Further Study of the Anaesthetic Properties of Fluothane. Anesthesiology 19. 38 (1958)

5 Long, J P., \& Pittinger, C. B. Laboratory Observations on the Cardıovascular and Respiratory Effects of Fluothane Anesthesiology 19106 (1958).

6 Nickerson, M., Henry, J. W, \& Nomaguchi, G. M. Blockade of Responses to Epinephrme and Norepinephrne by Dibenamine Cogeners J. Pharmacol \& Exper. Therap. 107 300-309 (1953).

7. Paton, W. D. M, \& Zammls, E. J. Paralysis of Autonomie Ganglia by Methonium Salts. Brit J. Pharmacol. 6: 155 (1951).

8 HaLl, L. W'Release of Adrenergic Catechols after Hexamethonium Bromide. Brit. J. Anäesth. 29: 294 (1957).

9. Guyton, A. C., \& ReEder, E. J. Quantitative Studies on the Autonomic Actions of Curare. J. Pharmacol \& Exper. Therap. 98. 188-193 (1950).

10. Courtice, F. C., \& Douglas, C. G. The Ferricyanıde Method of Blood-Gas Analysis. J. Physiol. 105. 345 (1947).

11. Jornstone, M. Cyclopropane Anaesthesia and Ventricular Arrhythmias. Brit. Heart J. 12239 (1950).

12 Johnstone, M. The Human Cardio-Vascular Response to Fluothane Anaesthesia. Bnt. J. Anaesth 28(9): $392(1956)$.

13. Stephen, C R, Grosskreutz, D. C, Lawrence, J H H., Fabian, L. W.; BourgeoisSavardin, M.; \& Coughiın, J Evaluation of Fluothane for Clinical Anaesthesia. Canad. Anaesth. Soc J. 4(3). 246 (1957).

14. Harris, T. A. B. Mode of Action of Anaésthetics. 1st ed. Edmburgh: Livingstone (1951). 